\title{
An experimental study of silt scouring
}

\author{
T. J. PEIRCE, R. T. JARMAN \& C. M. de TURVILLE
}

\section{Mr Jarman}

We decided to study silt scouring because power station cooling water may be drawn into the intake through an open channel or through a tunnel; a channel is cheaper to build but may suffer from siltation and so may need dredging, which can be very costly. Clearly, a better understanding of the siltation process could lead to significant savings in the cost of future stations.

43. A substantial part of our investigation is described in the Paper and I will only mention briefly the reconstitution tests described in \$\$ 4-16. In addition some work was done on the measurement of shear strength with a vane shear meter and on the effect of hydrostatic pressure on the compaction of muds, and a paper on the sedimentation of muds was published in the Proceedings of this Institution in 1966. ${ }^{2}$ Dr Peirce will describe aspects of this work and some recent calculations on the shear force needed to scour muds from stable estuary inlets.

44. Three problems deserve further attention: the erosion of mud by water waves, the effect of bed slope on erosion rates, and the natural hydrodynamic roughness of the beds of rivers, estuaries and coastal waters. I hope that contributors will mention some progress on these problems.

\section{Dr Peirce}

The described studies have shown that the measured fluid shears necessary for sustained erosion were in the range $16-50 \mathrm{dyn} / \mathrm{cm}^{2}$ and, exceptionally, up to about 160 $\mathrm{dyn} / \mathrm{cm}^{2}$. In order to demonstrate that these values are realistic, reference is made to the work of Bruun and Gerritsen. ${ }^{5}$ These authors examined data for a number of stable tidal inlets and showed a relationship between measured values of maximum tidal flow, $Q_{\mathrm{m}}$ (spring tide conditions) and the corresponding channel cross-sectional area, $A$. The relationship was of the form:

$$
Q_{\mathrm{m}}=A C \sqrt{ } \tau_{\mathrm{g}} / \rho g \quad . \quad . \quad . \quad . \quad . \quad . \quad . \quad .
$$

where $\rho$ is the fluid density and $g$ the acceleration due to gravity. $C$ is a roughness coefficient given by the equation:

$$
C=30+5 \log A \quad\left(A \text { has the dimensions of } \mathrm{m}^{2} ; C, \mathrm{~m}^{1 / 2} \mathrm{~s}^{-1}\right) \quad .
$$

$\tau_{\mathrm{a}}$ is defined as the stability shear stress which may be considered as the maximum shear applied under spring tide conditions and that necessary to remove previously deposited material, i.e. to maintain channel stability. From the measurements, the deduced average value of $\tau_{B}$ was approximately $38 \mathrm{dyn} / \mathrm{cm}^{2}$. This level of $\tau_{B}$ is similar to those measured in the current work.

46. The relevance of spring tide conditions to channel stability was further demonstrated by studies of the erosion/deposition characteristics of Portishead mud on the estuary foreshore. Measurements were made of the variation of mud level with time and it was established that there was a cycle of erosion and deposition with maximum erosion occurring under spring tide conditions.

47. Measurements were made of the sedimentation properties of a range of estuarine muds and the results have been described fully in an earlier paper. ${ }^{2}$. In particular, it was shown that the muds existed as flocs, containing groups of solid particles with occluded water. From an analysis of the variation of sedimentation

Paper published: Proc. Instn civ. Engrs, 1970, 45 (Feb.) 231-243. 
velocity with solids concentration, the average floc density and diameter were estimated.

48. Vane shear strength measurements were made of muds 'on site' and reconstituted in the laboratory. Field experiments showed that shear strengths were approximately seven times higher than those measured in the laboratory indicating that, in the former environment, the muds acquire additional strength. There was no direct relationship between shearing strengths, $\tau_{v}$, and the corresponding values of fluid shear, $\tau_{H}$, necessary for sustained erosion. An attempt was made to relate laboratory measurements of $\tau_{\mathrm{H}}$ and $\tau_{\mathrm{v}}$ by the use of a cohesion index defined as the ratio of floc diameter $d_{\mathrm{r}}$ to primary particle diameter $d_{\mathrm{p}}$, obtained from sedimentation tests. A plot of $\tau_{\mathrm{v}}$ against $\tau_{\mathrm{H}} /\left(d_{\mathrm{r}} / d_{\mathrm{p}}\right)$ yielded a smooth curve (Fig. 9) but there was insufficient information to assess the physical significance of the relationship.

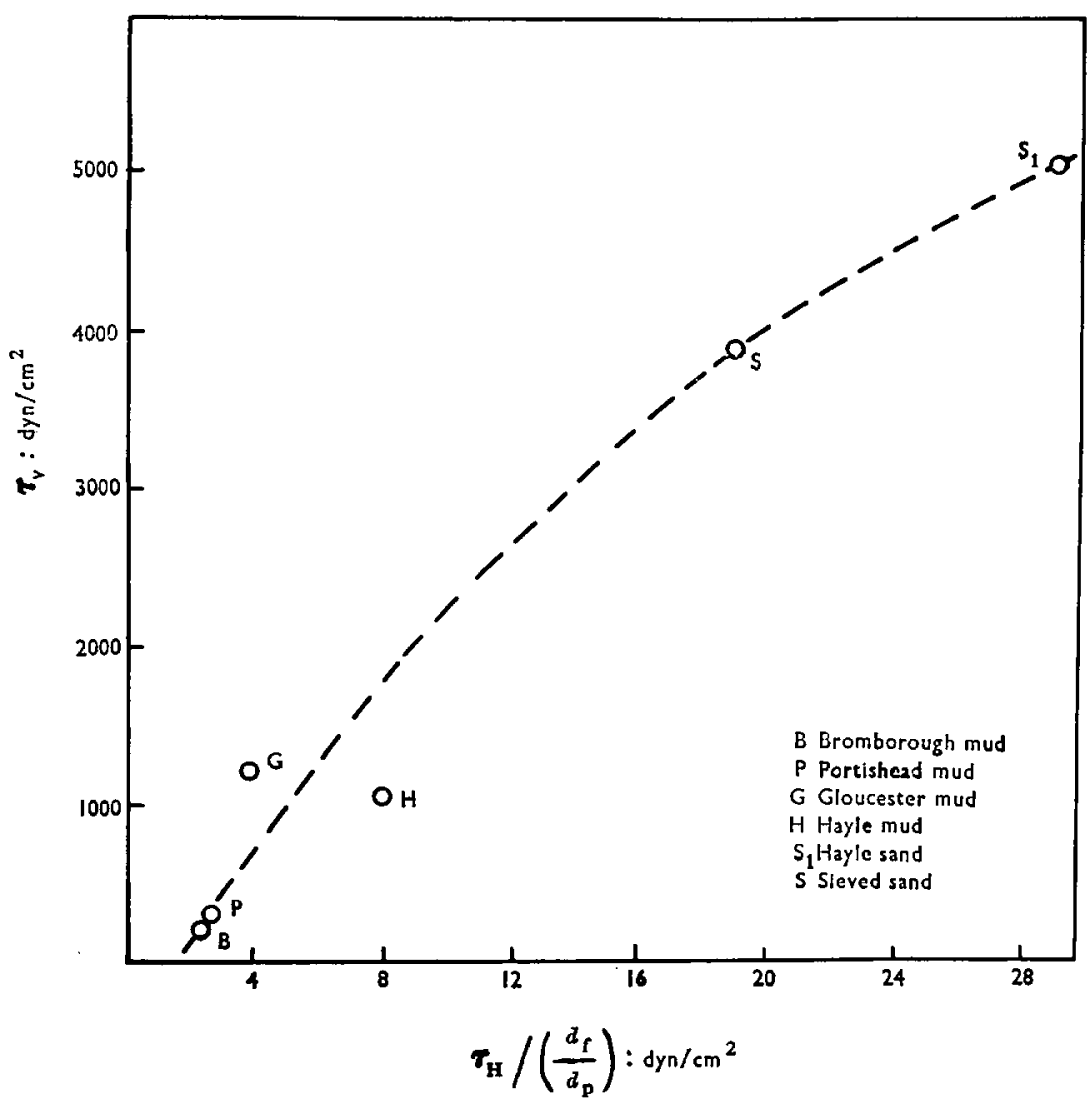

Note: dashed curve calculated from $C=6.2\left(\frac{1-e^{-t / 42}}{1+e^{-t / 42}}\right)$

Fig. 9. Relationship between vane strength, $\tau_{v}$ and $\tau_{\mathrm{H}} /\left(d_{\mathrm{f}} / d_{\mathrm{p}}\right)$ for cohesive muds and sands 
49. One feature of the current programme was the use of a drag plate for direct measurement of fluid shear on the bed of a $42 \mathrm{~cm}$ wide channel. A flat, Perspex plate $(7.5 \mathrm{~cm} \times 2.5 \mathrm{~cm})$ was supported horizontally on the tip of a vertical metal strip (11 cm long, $1.4 \mathrm{~cm}$ wide, $0.05 \mathrm{~cm}$ thick) attached to the under surface of the plate. The lower end of the strip was clamped to a rigid block. A shearing force applied over the top surface of the plate causes a small displacement of the plate and induces a bending moment in the strip. The surface stresses at the two sides of the strip are proportional to the bending moment, and both stresses are measured by a strain gauge attached to the surface. The change in resistance of the gauges unbalances an electrical bridge network and the out of balance current in the bridge is a measure of the drag force on the plate. The plate, strip and block were positioned in a Perspex well, the gap between the plate and the sides of the well being approximately $0.3 \mathrm{~cm}$. The assembly was mounted centrally in the channel, so that the top of the plate was flush with the channel bed. The well was filled with mercury to the level of the plate. The top surface of the plate was coated with a mixture of ground mud and paint, in order to simulate the roughness of the bed of the channel.

50. Under uniform flow conditions in the channel there was close agreement between the fluid shear computed from the uniform flow formula and that given by the plate. The channel roughness, $n$, calculated from the Manning equation, was $n=0 \cdot 014$. To check the roughness, the channel was enclosed to form a rectangular pipe and the pressure drop along the pipeline was measured for various flow conditions. From the results, the pipe friction factor was calculated and found to correspond to a Manning roughness $n=0.014$. Some measurements were also made of the velocity distribution in the channel and the derived shear was in close agreement with the shear given by the drag plate.

\section{Mr M. W. Owen, Hydraulics Research Station, Wallingford}

Fundamental research on very similar lines to the work reported by the Authors is in progress at the Hydraulics Research Station, but with a slightly different emphasis on the type of problem being investigated. Naturally the Authors have been concerned mainly with problems likely to be encountered in the operation of power stations, whereas at Wallingford the aim has been to obtain a better understanding of the cycle of processes of silt movement in an estuary.

52. In power station problems the type of erosion involved is relatively rapid, so that material which may be deposited in intake or outfall channels during periods of slack water will be readily removed during periods of high currents. This type of erosion can be readily observed, and tests in a relatively simple flume can yield meaningful results, as shown by the Paper. Incidentally, similar tests carried out at Wallingford on Medway muds yielded shear stresses varying from 24 to $58 \mathrm{dyn} / \mathrm{cm}^{2}$, which is within the range found by the Authors.

53. Erosion in the natural channels of an estuary is much more gradual, and fairly elaborate recirculating flumes are necessary to obtain measurements of the rates of erosion at given shear stresses. Such equipment is available at Wallingford and has been used recently to test Thames mud. The difference between the types of erosion is well illustrated by the fact that the critical shear stress for gradual erosion of Thames mud is only 3-4 dyn $/ \mathrm{cm}^{2}$. There is therefore a danger of applying published shear stress values to a particular problem without first checking that the published values refer to a similar type of erosion.

54. The results of the Thames mud tests were used to develop a mathematical model of silt movement in the whole of the Thames Estuary, and this model satisfactorily reproduced the variation of suspended concentration during a tide for both spring and neap tides. It also reproduced the behaviour of the bed during the tide and the formation of mud reaches, and was used to assist in predicting the effect that any proposals for a Thames flood prevention barrier would have on the location of the mud reaches. 
55. To me and, I think, to most people interested in the movement of silt, the most important and significant result of the Authors' work arises from their circular flume studies because, as far as I know, this is the first attempt that anyone has made to carry out identical tests on a bed of silt in its natural environment and in the laboratory. The fact that the results show that there was very little difference between the two will be welcomed by all workers, because this will enable all the tests to be carried out in relatively closely controlled conditions, which are essential to obtain an understanding of the basic principles involved. Although the Authors have not said so, I presume that the laboratory test beds had the same bulk density as did the beach beds.

56. Another matter of interest regarding the circular flume tests was the fact that at a constant paddle speed, the Authors found that the concentration approaches an equilibrium value. They state that this is when deposition and erosion are equal to each other. Have they any proof that deposition is occurring simultaneously with erosion? In the past, there has been a great deal of controversy about whether erosion and deposition can occur simultaneously in silts. Krone ${ }^{6}$ and Partheniades ${ }^{7}$ have opposing views on this and both claim to have supporting experimental proof.

57. If there is a possible explanation other than the fact that deposition and erosion are equal, it may be that the shear strength of the silt bed is likely to increase with increasing distance from the surface into the bed and the constant concentration could be due to the fact that the silt bed will erode only down to the layer at which its shear strength is equal to the shear stress exerted by the fluid. This is something that has still to be resolved.

58. The Authors derived from their application the expression for the time variation of concentration during tests, Fig. 3, which seems to fit their data fairly well. In deriving that expression, they have implicitly assumed that the settling velocity of silt was independent of the concentration, whereas results of tests which we have carried out show that this is definitely not the case, even in the concentration ranges to which the Authors found the expression to relate.

59. For instance, from both laboratory tests and field tests carried out with a new instrument which has been developed, it was found that settling velocity could vary from the square root of the concentration for Avonmouth silt to the square of the concentration for Thames silt during periods of low turbulence. I have, therefore, tried to recalculate the Authors' expression for the settling velocity varying linearly with concentration.

60. Figure 10 shows the data of Fig. 3 replotted, and the dashed line has been plotted with the settling velocity, $v_{B}$, linearly proportional to the concentration, $C$. It would have been better to plot this graph for a settling velocity proportional to the square root of concentration, which was what was found for Avonmouth mud only a few miles from Portishead, but that is rather involved and I have not completely succeeded in solving it. It can, however, be seen that whether or not the settling velocity is a function of concentration has relatively little effect on the shape of the curve.

61. In the Appendix, the Authors state that this type of curve did not fit their high concentration values because of their assumption that the settling velocity was independent of concentration. Fig. 10 would seem to indicate that the curve is not significantly different. Could the Authors show how the concentrations varied with time during their tests when they had very high suspended concentrations?

62. In the closing paragraphs of the Paper, the Authors state that they attempted to correlate the shear stress for erosion with the properties of the silt, but I contend that they have neglected most of the properties which I would consider to be essential in achieving such a correlation. For instance, their table of properties includes no measure of the bed density or its moisture content and there is no measure of the tensile strength, although this is partly covered by their introductory words about the vane shear tests. They could have measured the tensile strength rather better by plasticity index or even a viscosity type test (see $\$ 64)$. Furthermore, there is no 


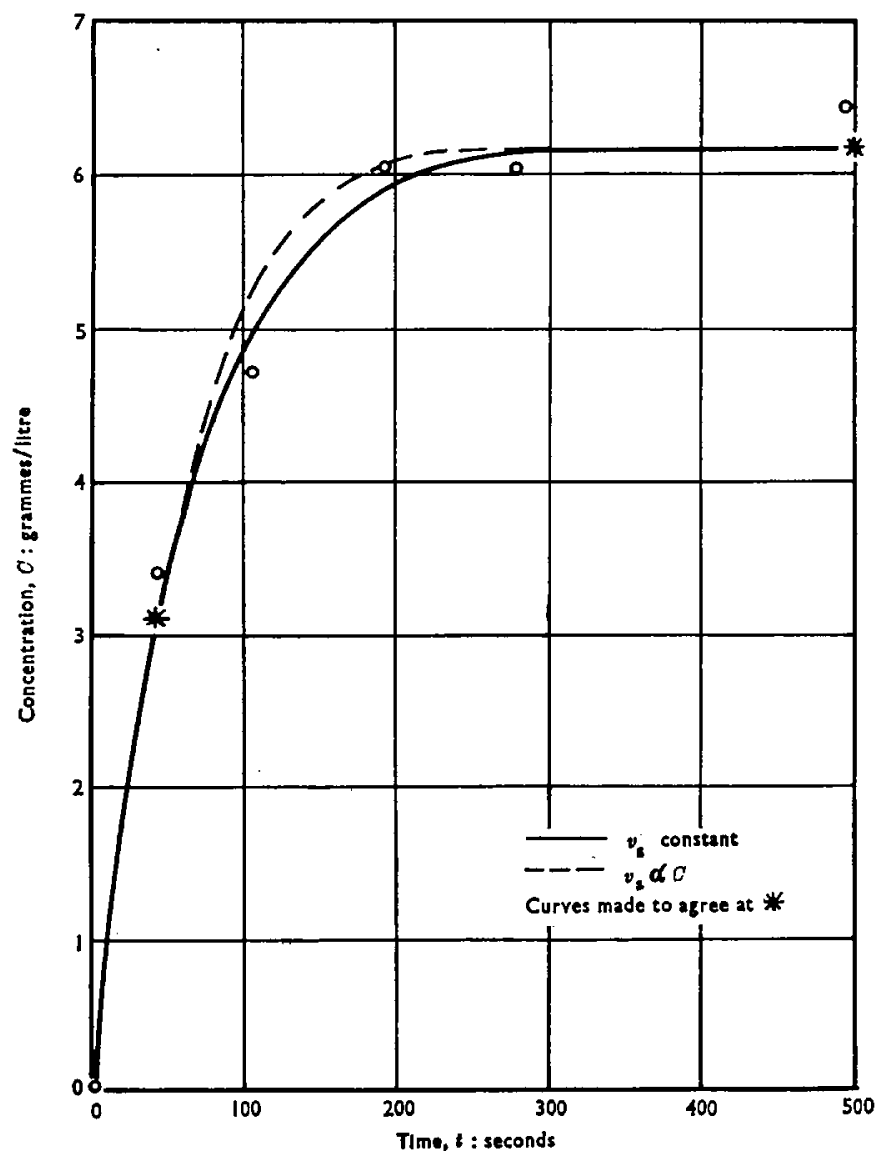

Fig. 10. Variation of silt concentration with time

mention of the chemical or mineralogical properties of the silt or the salinity of the water, all of which could give an idea of the interparticle cohesive forces. The Authors would probably have achieved more success if they had taken some or all of these into account.

63. With reference to the Introduction, the Authors' vane shear test shows that there is not a great deal of correlation between the hydraulic shear strength of the bed and the vane shear strength of the bed. This was proved fairly conclusively by Partheniades, ${ }^{7}$ who tried silt beds with vane shears in a ratio of nearly 100:1 and found that the ratio in a hydraulic shear was only about $1: 2$.

64. I mentioned in $\S 62$ the possible use of viscosity tests to determine the properties of the silt. These do not give viscosity measurements for the silt, but use a rotating viscometer to measure the drag on a cylindrical drum immersed in consolidated mud beds. For some time I have felt that these tests would give an indication of the tensile strength of the bed, and carried them out on different silts. Migniot, ${ }^{8}$ allowed mud beds to consolidate around the viscometer drum and measured the drag 
after various times of consolidation. He found that the shear stress exerted by the silt on the drum was of the same order as the hydraulic shear strength. In fact, the hydraulic shear strength was about half the viscosity shear strength, if one can call it that, whereas it is typically about one-seventh of the vane shear strength.

65. Migniot included in his paper the results of work on the erosion of silt under waves, and also on the stability of sloping banks.

\section{Professor J. R. D. Francis, Imperial College}

The Paper is to be commended as one of the very few accounts available on the hydraulic properties of mud. The knowledge of these cohesive sediments is totally inadequate for engineering purposes, and even though there were weaknesses in the experimental procedures given in the Paper, it should be regarded as a definite step forward.

67. The ingenious circular flume, and its method of observation using laboratory reconstituted mud is novel. Much additional work is necessary to determine the reason for the scatter in the results.

68. In the straight flume experiments there are several details which are not clear. In $\$ 22$, reference is made to increasing water flows until mud erosion occurred. What was the criterion of erosion starting? With clear water being fed into the flume, it might be supposed that the very fine clay particles would cause a cloudiness almost by molecular diffusion, irrespective of any transverse velocity.

69. In addition, the methods of finding shear stress can be disputed. A measurement of surface velocity is a very inexact criterion, since it may be controlled by secondary currents quite unaccounted for by the analysis of Appendix 2. In $\$ 24$, there is a distinctly erroneous idea that shear stresses are somehow different in subcritical velocity flows from supercritical flows. This is not so: the dynamic state of the flow is quite independent of its frictional state, and the same methods of assessment are applicable. It is also not clear where the hydraulic jump occurred in these observations.

\section{Mr P. Ackers, Hydraulics Research Station}

I feel that publication of studies of the performance of muds is important. At the Hydraulics Research Station we identified a need for research in this topic five or more years ago and we have been doing work in this field as staff and other commitments permitted, including building some rather more elaborate equipment than the Authors had available. I am hopeful that the results of our research will be published in the open literature.

71. The Authors' approach is quite intriguing, especially their use of the circular flume so that they could carry out in situ experiments on undisturbed mud, and also corresponding tests with precisely the same equipment in the laboratory. However, I am puzzled with regard to Fig. 4, and the text which explained it, as to whether there were four separate tests in the field and four separate tests in the laboratory, or whether there were two in each case. Also, were progressively greater speeds applied to a single bed or was it reconstituted from time to time?

72. Looking at the laboratory data plotted on the right-hand side of Fig. 4, it appears to me that there may be a significant difference between the test results from one series as compared with the other series of tests. Can the Authors explain such a difference, if they agree that it occurs? I suggest that the collection of points lying to the right of the plotted curve may relate to one test, whereas all the points that lie to the left of that plotted curve relate to another test. If my interpretation of the data is correct, these are sufficiently far apart for one to wonder why the results are so different.

73. That would not alter the fact, however, that a fair measure of agreement was found between the erodibility of the mud in situ and when reconstituted in the laboratory. This agrees with work carried out at the Hydraulics Research Station when 
studies were made of mud in Damhead Creek, which is a tributary of the Medway. Tests were made on this mud in a flume, using undisturbed samples from the field to pave the bed of the flume. At one stage in the experiments we found that the water content of the mud had dropped because of drying out, and we felt that water content was so vital to the performance of the mud that we added water and of necessity reconstituted the mud. There was no measurable difference in the shear stress as a result of doing this.

74. That leads me to ask whether, in the Authors' tests, the water contents were the same in the field as in the laboratory. I found this a significant omission from the data in the Paper, because it would be anticipated that the degree of consolidation and compaction that exists (water content is a measure of this) would significantly affect the shear strength.

75. I would like to comment on the assumption, in $\S 24$, of the value of $n$ of 0.025 in order to compute the shear under certain conditions. During a series of tests at Wallingford on a fresh water mud, we deduced the roughness of the bed. This was expressed in terms of the equivalent sand roughness, $k_{\mathrm{s}}$, and eight individual tests on mud beds after various periods of consolidation yielded $k_{s}$ values between 0 and $0.025 \mathrm{ft}$ at the point of rapid erosion. These are equivalent to a smooth surface, and a value of $n$ of about 0.017 , respectively. The latter value corresponded to a somewhat undulant surface to the bed, whereas in the test which yielded $k_{\mathrm{s}}=0$ the bed was described as plane, smooth and firm. Intermediate values of $k_{\mathrm{s}}(n \simeq 0 \cdot 012)$ were obtained when the bed, though fairly smooth in appearance, was described as soft. It would clearly be incorrect to assume that one Manning's $n$ value can be applied to any mud surface, and I suspect that a figure of 0.025 is beyond the range to be expected for a regular deposit.

\section{Mr G. E. Tuck, Central Electricity Generating Board}

Mr Jarman stated that the work was applicable to power station intakes. I wonder whether, with the differences that were found in the mud at Oldbury, Portishead, Brean, and so on, the Authors could design a power station intake to take a particular flow into a pump house at low water? If so, I should be pleased to see the difference in design in cross section dictated by the different muds.

77. Second, I wonder whether, as Mr Peirce indicated, the same differences in cross section might arise by observing low water channels in these areas which, presumably, it was said, changed the shape. I understood the shape of the low water channel at spring tide would change according to these different muds. Therefore, if these were observed, would the same answer be obtained as the channel section designed from these studies?

78. Having now, perhaps by observation or by design, arrived at a channel section, there is the difficulty that the pumps are pulling down the channel and not delivering down the channel, so that a very small obstruction (a small deposition of material of a somewhat different nature, perhaps, than the optimum design mud which is being studied) settling at the end of the channel could block it completely because the pumps obviously cannot lift water over the obstruction at the end of the channel.

79. The Paper has increased the understanding of the behaviour of mud, but I query its relevance to power station intakes.

\section{Mr A. J. M. Harrison, Hydraulics Research Station}

With reference to Fig. 8, pp. 238-9 and Appendix 2 (calculations of shear in the flume tests) it seems unlikely that a logarithmic velocity profile would occur in such a short distance down the flume. The flow straightener might produce an initially distorted profile, but even if it produced a uniform velocity profile at the upstream end, a logarithmic profile would not be established throughout the depth within the length 
of the flume. I suggest that the shear value should have been calculated by boundary layer theory, but nevertheless a certain doubt would still remain, because the effect of the turbulence created by the flow straightener at the upstream end of the flume would not be known exactly. Have the Authors considered this point?

81. Would the Authors explain their reasons for the statement in $\S 17$ that the calculation of shear refers only to the subcritical and not to supercritical flow?

82. One of the subjects for research suggested by Mr Peirce was erosion by water waves. Migniot's work ${ }^{8}$ has been mentioned, but there is certainly much scope for further work in this field. A particular project with which $I$ have been concerned involved this point, in a study that was carried out on the River Plate, ${ }^{\theta}$ where the bed of the estuary, which was fresh water, consisted of a mud. The mud was surprisingly resistant to erosion under the combined action of waves and tidal currents. However, another interesting point is that the effect of waves in a muddy estuary can also be to maintain in suspension material that would not be so maintained if there were only tidal currents effective in producing shears or velocities near the bed.

83. Owen has written a paper ${ }^{10}$ concerning the effect of a barrage on silt movement in an estuary.

\section{Mr B. A. O'Connor and Professor D. M. McDowell, University of Manchester}

When used on intertidal deposits, the channel was presumably topped up with water to allow for seepage through the bottom. In the laboratory, however, there appears to have been no provision for seepage through the bottom of the channel. Did this, in fact, have a solid floor? If so, is there not a significant difference between conditions in the field and in the laboratory that would limit the application of the flume to the study of nearly impervious sediments?

85. The Authors find good agreement between the behaviour of fine sediments in the field and the same sediments reconstituted in the laboratory. This is not altogether surprising, because the fine superficial sediments in an estuary will probably have been reconstituted by tidal flow only a few hours before the test. The agreement would not be so good between consolidated sediments well below the surface of the mud and their reconstituted equivalents.

86. There have been many other attempts to study the characteristics of marine sediments. Some of these have been reviewed by Postma. ${ }^{11} \mathrm{He}$ drew attention to the results of work done before 1960 which showed the importance of minerals such as kaolinite, illite, montmorillonite and chloride in relation to the alkylinity of the water. Montmorillonite, for example, has a high ionic bond strength and may require a relatively high critical shear to initiate erosion. The variations in clay minerals can be studied with the aid of X-ray diffraction tests. At a more empirical level, screen penetration or shear vane tests have been used by many other workers. If the Authors had used such tests on their samples, their results could have been compared with results obtained by others. ${ }^{7}$

87. Postma also referred to work done during the Demarara Coastal Investigation $^{12}$ using a circular flume with flow induced by paddles. Later workers abandoned paddles and used instead an annular ring immersed in the surface of the water. Rotation of this ring produced more uniform flow conditions than could be achieved using paddles. ${ }^{7}$

88. In Appendix 1 (equation (iii)), the Authors present an expression for the variation of concentration with time in their miniature flume. In their method of derivation, the Authors assume that the variation of concentration with depth was zero at any instant of time, i.e., the concentration increased at all levels simultaneously. If a fall velocity term is to be used in the description of the deposition rate, then the only way in which the concentration can change simultaneously throughout the depth is for the applied shear to be infinite. 
89. An alternative method of derivation would be to use the general diffusion equation, which is written in cartesian co-ordinates as:

$$
\frac{\partial C}{\partial t}=\sum_{i=1}^{3} \frac{\partial}{\partial x_{i}}\left(\epsilon_{i} \frac{\partial C}{\partial x_{i}}-u_{i} C\right) .
$$

where $i=1,2,3$, the three cartesian co-ordinates, $x_{i}=$ a length dimension in the $i$ th direction, $\epsilon_{i}=$ a diffusion coefficient in the $i$ th direction'and $u_{i}=$ the convective velocity in the $i$ th direction. The term $\epsilon_{i} \partial C / \partial x_{i}$ represents the transport of sediment from an area of high concentration due to the turbulence within the flow, while the term $u_{i} C$ represents the convection of sediment due to the fluid velocity $u_{i}$.

90. In the Authors' case, the flume paddles were large enough to give complete mixing across the flume width. Thus, if $x_{1}$ is measured vertically upwards from the bed, $x_{2}$ is measured in the direction of mean flow and $x_{3}$ is measured horizontally across the flow, $\partial C / \partial x_{3}=0$ and all terms involving $i=3$ are lost from equation (3). Similarly, if the sediment is being eroded equally at all points around the flume bed, then $\partial C / \partial x_{2}=0$ and all terms involving $i=2$ are lost. If, for $i=1$, the co-ordinate origin is considered to be at the surface of the mud, then $u_{1}$ will be equal to $-\bar{v}_{\mathrm{s}}$. Equation (3) thus reduces to the simple form:

$$
\frac{\partial C}{\partial t}=\frac{\partial}{\partial x_{1}}\left(\epsilon_{1} \frac{\partial C}{\partial x_{1}}+\bar{v}_{\mathrm{s}} C\right) . . \quad . \quad . \quad . \quad .
$$

91. The first term within the bracket of equation (4) represents the vertical transport of sediment from the high concentration region near the flume bed: in the limit it represents the pickup of particles from the bed. The second term represents the transport of sediment towards the bed due to the effect of gravity on the sediment particles.

92. If the turbulence characteristics can be specified, i.e., if the variation of $\epsilon_{1}$ with depth can be described, then equation (4) can be solved either analytically or by finite difference means. For the case of $\epsilon_{1}$ constant with depth, the analytical solution has been given by Dobbins, ${ }^{13}$ while $O^{\prime} C^{\prime}$ nnor ${ }^{14}$ has presented a solution for the case of a parabolic distribution of $\epsilon_{1}$ with depth. If $\bar{v}_{\mathrm{s}}$ is an arbitrary function of depth or concentration, then equation (4) is, best solved by the finite difference method.

93. Equation (4) has been applied to the Authors' results shown in Fig. 3, using a computer program written as part of a research programme (at Manchester University) dealing with sediment diffusion. In order to do this it was assumed that both $\epsilon_{1}$ and $\bar{v}_{\mathrm{s}}$ were constant with depth. The value of $\bar{v}_{\mathrm{s}}$ was calculated from equation (iii) in Appendix $1, \S 38$, as $\bar{v}_{3}=h / 64=0.078 \mathrm{~cm} / \mathrm{s}$. The value of $\epsilon_{1}\left(1.833 \mathrm{~cm}^{2} / \mathrm{s}\right)$ was found from the formula ${ }^{14}$ :

$$
\epsilon_{1}=\beta K u_{*} h / 6 .
$$

where $\beta=$ ratio of the sediment to momentum transfer coefficients $=1 \cdot 0, K=$ von Karman's constant $=0.4$ at the low concentration used, $u_{*}=$ shear velocity $=(\tau / \rho)^{1 / 2}$, $\tau=$ shear stress on the flume bed, $\rho=$ water density and $h=$ water depth $=5.0 \mathrm{~cm}$. The shear velocity was calculated using a value for the shear stress of $30 \mathrm{dyn} / \mathrm{cm}^{2}$, i.e., similar to the Gloucester mud case.

94. For this computation it was also assumed that the rate of pickup from the bed was constant at all times between $t=0$ and $t=\infty$ and equal to the value at $t=\infty$, i.e., by putting $\partial C / \partial t=0$ in equation (4) the rate of pickup from the bed is given as:

$$
\left.\epsilon_{1} \frac{\partial C}{\partial x_{1}}\right|_{\text {bed }}=-\left.\bar{v}_{3} C_{\infty}\right|_{\text {bed }}
$$

The value used for $C_{\infty}$ was estimated from Fig. 3 as $6.5 \mathrm{~kg} / \mathrm{m}^{3}$. The variation of concentration with depth at $t=\infty$ may be found directly by integrating equation (6), i.e.:

$$
C\left(x_{1}\right)=C_{\infty} \exp \left[-\bar{v}_{\mathrm{s}} x_{1} / \epsilon_{1}\right] . \quad . \quad . \quad . \quad . \quad .
$$




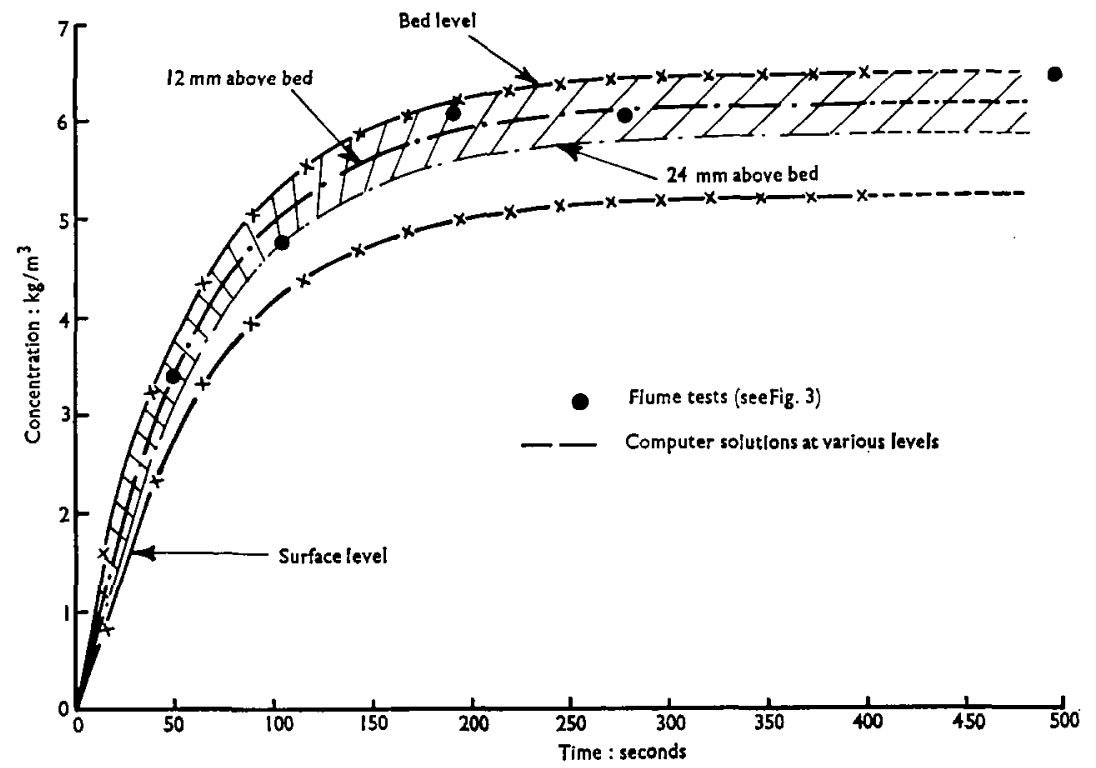

Fig. 11. Comparison of computer and miniature flume results

95. The results from the computer output are shown in Fig. 11 together with the experimental points taken from Fig. 3. It is apparent that all the experimental points lie on or within the hatched area, the limits of which represent the concentration-time curves for the bed level and a level $24 \mathrm{~mm}$ above the bed. It should be noted that the sampling orifice appears to be about $15 \mathrm{~mm}$ above the mud bed. Since the pipette sampler will have drawn fluid from either side of the $15 \mathrm{~mm}$ orifice level, with a possible bias towards the layers below the orifice level, because of the sampling angle, the variability of the samples can be explained by a variation in the sediment concentration with depth.

96. Figure 11 shows the concentration-time curve for a level of $12 \mathrm{~mm}$ above the mud bed which is very similar to the Authors' proposed relationship given in Appendix 1. The steady-state concentration is $6.17 \mathrm{~kg} / \mathrm{m}^{3}$ compared with $6.2 \mathrm{~kg} / \mathrm{m}^{3}$ as used by the Authors. This agreement between the $12 \mathrm{~mm}$ level and the Authors' relationship again supports the view that the mean sampling level was slightly below the $15 \mathrm{~mm}$ level of the pipette orifice. The results given by equation (3) are thus at least equal to those suggested by the Authors but also take into account the finite settling velocity of the sediment particles.

Mr E. J. Humby, Portsmouth Polytechnic and Mr N. B. Webber, Southampton University

Since the 1960s the field of sediment transport has been made the subject of systematic study. ${ }^{7}$ Perhaps the principal reasons are to be found in the considerable complexity of the problems posed and their interdisciplinary character. ${ }^{15}$ In the broadest sense, they embrace oceanography, hydrology, particle physics, colloidal chemistry, mineralogy, soil mechanics, and hydrodynamics.

98. The Paper emphasizes some of the experimental difficulties associated with the study of the erosion of cohesive material, and in particular the definition of erosion 
rates, the evaluation of hydrodynamic forces on sediment particles, and the difficulty of preparing erosion beds that are truly representative of estuarine deposits.

99. The literature distinguishes between two forms of erosion: surface erosion and mass erosion of the type described as having occurred in the Authors' flume. Surface erosion of clay particles and flocs appears to have little correlation with the gross shear strength of the bed material, but may be dependent on the surface activity of the mineral particles, their previous flocculation history and the turbulence structure of the flow. There is some evidence to show that mass erosion may be related to ageing, or thixotropic increase in the shear strength of the bed material. It would be of interest to know if such a distinction between the two types of erosion was apparent during the Authors' experiments and if it were possible to establish a paddle speed at which no erosion occurred.

100. It is rather surprising that the Authors did not consider it necessary to conduct the flume tests with saline water, since this has been the practice of certain other investigators. In fact, it was found by Migniot ${ }^{8}$ that the velocity needed to scour a mud in salt water was nearly twice as great as that for the same mud deposited in fresh water.

101. Turbulence is an important factor in the case of the erosion of a fine sediment, particularly since the velocity required to maintain a suspension is much less than that needed to entrain it. Owing to contamination problems, the conventional method of turbulence measurement by hot-film anemometry is not usually satisfactory for application to a dilute suspension. However, a new laser technique developed by Greated ${ }^{16}$ offers considerable promise; it would appear that not only can the Reynolds stresses be measured but also the concentration, both without any interruption of the flow.

102. This question of turbulence intensity is of particular significance to the natural situation, because of the agitational effect of waves. It would be interesting to know if the Authors have established any correlation between the erosion of sediment and the degree of wave action.

103. From what has been said, it is evident that there are many aspects that need to be considered, including the additional problems of depositional processes, angles of repose, and density flows. Research on all these matters is of particular relevance to harbour maintenance and improvement. A few years ago it was stated ${ }^{17}$ that the annual budget for maintenance dredging in the United Kingdom was $£ 7.5$ million, to which must be added the considerable capital cost of improvement schemes needed to accommodate ships of ever increasing draught. In the light of this order of expenditure and the many practical uncertainties, there is little doubt that much greater support needs to be given to basic research on the lines that the Authors have commendably initiated.

\section{T. J. Peirce, R. T. Jarman and C. M. de Turville}

The various participants to the discussion have raised many important questions of undoubted relevance to our work, and we are most grateful for their comments. Some of the difficulties mentioned were inherent to the nature of the investigation, and the field work was generally carried out under difficult environmental conditions which did not favour the use of refined techniques. However, despite these limitations the work did clarify a number of points.

105. The limited experimental data on the variation of Portishead silt concentration with time agreed sufficiently well with our theoretical curve at low concentrations to suggest that the sedimentation velocity was approximately constant as assumed for dilute suspensions. However, $\mathrm{Mr}$ Owen has pointed out that the sedimentation velocity of $v_{\mathrm{s}}$ of some muds is related to concentration $C$ according to the approximate empirical relation $v_{\mathrm{s}}=\alpha C^{n}$ where $\alpha$ and $n$ depend on the nature of the sediment. Thus the deposition rate $D=C v_{\mathrm{s}}=\alpha C^{n+1}$. 
106. With this expression, equation (ii) becomes:

$$
\frac{\mathrm{d} C}{\mathrm{~d} t}=\frac{1}{h}\left(E-\alpha C^{n+1}\right)
$$

For the values of $n$ of interest, and with $x=C / C_{\mathrm{T}}, t_{0}=h C_{\mathrm{T}} / E$, the solutions of this equation are:

$$
\begin{aligned}
& n=0 \quad x=1-\mathrm{e}^{-t / t_{0}} \\
& n=\frac{1}{2} \quad x\left[1+2 \sum_{m=1}^{\infty} \frac{x^{3 m / 2}}{3 m+2}\right]=\frac{t}{t_{0}} \\
& n=1 \quad x=\tanh \frac{t}{t_{0}} \\
& n=2 \quad \frac{1}{6} \ln \frac{x^{2}+x+1}{(1-x)^{2}}-\frac{\pi}{6 \sqrt{3}}+\frac{1}{\sqrt{3}} \tan ^{-1} \frac{2 x+1}{\sqrt{3}} \frac{t}{t_{0}}
\end{aligned}
$$

107. In Fig. 3, reasonable agreement between theory and experiment was obtained by taking $n=0$ and $t_{0}=64 \mathrm{~s}$. However, approximately the same degree of agreement can be obtained with $n=\frac{1}{2}, t_{0}=77 \mathrm{~s}$ or even with $n=1, t_{0}=84 \mathrm{~s}$. Since $t_{0}$ is an adjustable parameter, these experiments do not enable us to deduce how sedimentation varies with concentration.

108. Mr Ackers considered that some of the data for beach and laboratory homogenized mud shown in Fig. 4 appeared to be different. On re-examination of these figures, which were derived from four pairs of comparative tests, we found that in 3 out of 19 cases, relatively high concentrations were obtained with homogenized mud which were unmatched by beach muds tested at similar paddle speeds. In fact these three concentrations were all obtained during the same set of laboratory tests, and it is possible that the clearance between paddle and bed was slightly less than intended on the occasion.

109. Even so, a statistical analysis of all the numerical data used in Figs 4 and 5 gives for the least squares best fit:

$$
\begin{array}{ll}
\text { Beach mud } & \log _{10} C_{\mathrm{T}}=3.732 p+0.155 \\
\text { Homogenized mud } & \log _{10} C_{\mathrm{T}}=4.746 p-0.198
\end{array}
$$

where $p$ is the paddle speed in rev/s. A comparison of the two slopes, using the $t$ test, gives $t=0.884$ with 33 degrees of freedom, showing that there is no significant difference between these two slopes. Although it is quite possible that minor but significant differences might have been revealed by gathering more data and somehow reducing the scatter, our main concern was whether the strength of mud reconstituted in the flume differed from that laid down naturally in the estuary. A relatively small number of tests sufficed to show by and large that it did not.

110. The causes of the scatter of data are uncertain. The erosion rate is probably strongly dependent on the size of gap between the paddle and mud bed. A particular difficulty was the impossibility of achieving a uniform gap width in field tests, as the Portishead shore has a variable slope averaging about three degrees. A further source of variability was the difficulty of ensuring that the surface material collected was similar to the surface tested in situ.

111. The water content and bulk density were not determined during these tests, although it is now recognized that these would have been valuable indices of the voids ratio and degree of compaction, which could have a significant effect on the reproducibility of laboratory test results. However, the collected samples were kept under water until tested, so that freshly drained samples were investigated in both locations with similar but unknown water content. The muds used in the linear flume were tested for moisture content. Average values of moisture contents and voidages 
for different muds are given in Table 3, the voids ratio being defined as the volume of interstitial liquid per unit volume of solids.

Table 3. Bed conditions (average values with standard errors)

\begin{tabular}{|c|c|c|c|}
\hline \multicolumn{2}{|c|}{ Mud } & \multirow{2}{*}{$\begin{array}{c}\begin{array}{c}\text { Moisture } \\
\text { content, } \\
\%\end{array} \\
155 \pm 10 \\
71 \pm 4 \\
37 \pm 3 \\
61 \pm 3\end{array}$} & \multirow{2}{*}{$\begin{array}{l}\begin{array}{c}\text { Voids } \\
\text { ratio } e\end{array} \\
3.8 \pm 0.3 \\
1 \cdot 6 \pm 0.1 \\
0.9 \pm 0.08 \\
1.5 \pm 0.08\end{array}$} \\
\hline $\begin{array}{l}\text { Portishead } \\
\text { Gloucester } \\
\text { Bromborough } \\
\text { Hayle (mud) }\end{array}$ & $\begin{array}{llll}\cdot & \cdot & \cdot & \cdot \\
\cdot & \cdot & \cdot & \cdot \\
\cdot & \cdot & \cdot & \cdot \\
\cdot & \cdot & \cdot & \cdot\end{array}$ & & \\
\hline
\end{tabular}

112. The muds were received saturated with saline water and were reconstituted by homogenization in the linear flume. Under these conditions, line settlement ${ }^{2}$ was observed indicating that the reduced salinity was still adequate to allow the mud to exist in the form of a flocculant structure as in an estuarine environment.

113. No attempt was made to provide for seepage of liquid from the mud in the linear flume. We consider that this effect is negligible for the conditions under which the mud would be eroded in its natural environment, i.e. completely submerged in the estuary. However, contrary to the impression gained by Mr O'Connor and Professor McDowell, provision was made in the laboratory for the seepage of water through the base of the circular flume, which was placed in an oversize tray filled with sufficient mud to afford a clearance of 3-4 cm between the base of the Perspex wall and the bottom of the tray. Consequently, saline water had to be added between runs to compensate for seepage losses, so that the mud was at all times virtually saturated with water, as is indeed essential if the measurements are to be applicable to submerged sediments.

114. Experiments with the linear flume showed that the erosion behaviour of the test bed depended upon the level of applied shear. Tables 4 and 5 give details of the bed motion occurring at each level of shear. As Professor Francis pointed out, slight erosion can be observed even at very low flow rates, so that it is necessary to specify closely the criterion adopted to decide when significant erosion begins. The criterion we adopted was that there should be a sustained general erosion of the bed across one or more sections near the centre of the test bed. With the nomenclature of Table 4, this mass erosion occurs at stage $\mathrm{T}$, though a much lower fluid shear sufficed to initiate surface erosion at stage $D$.

115. The distinction between surface and mass erosion was apparent to some extent from our experiments, as Mr Humby and Mr Webber inquired, but was blurred somewhat by the existence of a range of intermediate phenomena. No study was made of any correlation between the erosion of sediment and the degree of wave action, though we underlined our awareness of this question in our introductory remarks.

116. The assumption of a logarithmic velocity profile (Appendix 2) has been questioned by Mr Harrison, who considered that the length of flume appeared to be too short in relation to its depth to permit the attainment of a fully developed turbulent flow anywhere in the flume. The depth of the flume itself should not be confused with the depth of the water flow, which was typically $0.03 \pm 0.005 \mathrm{~m}$ when erosion occurred. Therefore the distance of $3.32 \mathrm{~m}$ between the flow straightener and test section was approximately 100 times the depth, which is normally considered to be sufficient to achieve a fully developed turbulent flow. 
Table 4. Description of bed movement observed during straight channel tests

\begin{tabular}{|c|c|}
\hline $\begin{array}{l}\text { Code } \\
\text { letter }\end{array}$ & Description of bed phenomena \\
\hline A & Bed motion not detectable. \\
\hline B & $\begin{array}{l}\text { Discontinuous movement of granular material along surface of bed. } \\
\text { Motion confined to certain paths parallel to the direction of fluid flow. }\end{array}$ \\
\hline $\mathbf{C}$ & $\begin{array}{l}\text { Drift of apparently low density material in suspension close to bed surface. } \\
\text { Material is not granular but appears in form of strings of particles (flocs); } \\
\text { The paths taken by such material are unstable, and the material 'wanders } \\
\text { with time. The paths are mainly confined to the centre of the flume. }\end{array}$ \\
\hline $\mathbf{D}$ & Continuous movements of granular material along the bed. \\
\hline $\mathrm{E}$ & Formation of shallow dunes by the granular material. \\
\hline $\mathrm{F}$ & $\begin{array}{l}\text { Dune formation more prominent. Flat bed between dunes. The dunes } \\
\text { move in the direction of flow. The front of a dune is steeper than the rear. } \\
\text { Grains moving up the shallow slope of the dune are deposited at the foot } \\
\text { of the steep slope, and trapped by the advancing dunes. }\end{array}$ \\
\hline G & $\begin{array}{l}\text { Flaking of bed surface material. The bed surface consists of a skin } \\
(\sim 1 \mathrm{~mm} \text { thick }) \text {, which is broken into flakes }(4-5 \mathrm{~mm} \text { in length). }\end{array}$ \\
\hline $\mathrm{H}$ & $\begin{array}{l}\text { Development of scour runnels in the bed surface, running parallel to the } \\
\text { direction of flow. These are long shallow channels, either in the surface } \\
\text { material or (if the latter has fiaked) in the material immediately below the } \\
\text { bed surface. When they are first detected, runnels do not appear to be } \\
\text { continually enlarging. }\end{array}$ \\
\hline $\mathbf{J}$ & Rapid advancement of dunes. Crest of dunes in suspension. \\
\hline K & $\begin{array}{l}\text { Aggregates visible below eroded bed surface. Aggregates appear black in } \\
\text { colour, and have either smooth or rough surfaces. Their maximum size } \\
\text { approaches } 1 \mathrm{~cm} \text { (Portishead mud). Aggregates have a jelly-like con- } \\
\text { sistency, and slip when touched. }\end{array}$ \\
\hline $\mathbf{L}$ & Disappearance of dunes, giving the bed a smooth appearance. \\
\hline M & $\begin{array}{l}\text { Increase in number, depth and width of scour runnels. Material observed } \\
\text { to be scoured from the sides of these runnels. Scouring usually only } \\
\text { temporary. }\end{array}$ \\
\hline $\mathbf{P}$ & $\begin{array}{l}\text { Cracks in the bed appearing immediately upstream around perimeter of } \\
\text { exposed aggregates. }\end{array}$ \\
\hline Q & $\begin{array}{l}\text { No apparent bed movement (under conditions of comparatively high shear } \\
\text { rates). }\end{array}$ \\
\hline $\mathbf{R}$ & $\begin{array}{l}\text { Localized scouring. A deep scour hole or runnel has developed, but } \\
\text { scouring subsequently ceases. }\end{array}$ \\
\hline $\mathbf{T}$ & $\begin{array}{l}\text { General erosion of bed. Erosion is progressive across one or more sections } \\
\text { near the centre of the flume. }\end{array}$ \\
\hline
\end{tabular}




\begin{tabular}{|c|c|c|c|c|}
\hline \multirow[t]{2}{*}{ Phenomena } & \multicolumn{4}{|c|}{ Average shear $\tau\left(\mathrm{dyn} / \mathrm{cm}^{2}\right)$ at which phenomena occur } \\
\hline & $\begin{array}{l}\text { Portishead } \\
\text { mud }\end{array}$ & $\begin{array}{l}\text { Gloucester } \\
\text { mud }\end{array}$ & Hayle mud & $\begin{array}{c}\text { Bromborough } \\
\text { mud }\end{array}$ \\
\hline $\begin{array}{l}\text { A } \\
\text { B } \\
\text { C } \\
\text { E } \\
\text { D } \\
\text { Q } \\
\text { G } \\
\text { K } \\
\text { J } \\
\text { H } \\
\text { F } \\
\text { M } \\
\text { R } \\
\text { P } \\
\text { L }\end{array}$ & $\begin{array}{c}0 \cdot 013 \dagger \\
5 \cdot 2 \pm 1 \\
\text { Not detected } \\
6 \cdot 8 \pm 1 \cdot 7 \\
8 \cdot 6 \pm 0 \cdot 3 \\
8 \cdot 6 \pm 3 \cdot 0 \\
17 \cdot 9 \pm 4 \cdot 0 \\
25 \cdot 4 \pm 8 \cdot 0 \\
30 \cdot 2^{*} \\
30 \cdot 2^{*} \\
31 \cdot 8^{*} \\
\text { Not detected } \\
34 \cdot 4 \pm 6 \cdot 0 \\
35 \cdot 0 \pm 3 \cdot 1 \\
37 \cdot 0^{*}\end{array}$ & $\begin{array}{c}0 \cdot 13 \dagger \\
2 \cdot 7 \pm 0 \cdot 6 \\
3 \cdot 0 \pm 0 \cdot 7 \\
3 \cdot 6 \pm 1 \cdot 1 \\
1 \cdot 9 \pm 0 \cdot 7 \\
\text { Not detected } \\
8 \cdot 6 \pm 1 \cdot 1 \\
15 \cdot 9 \pm 6 \cdot 5 \\
11 \cdot 5 \pm 2 \cdot 8 \\
13 \cdot 5 \pm 3 \cdot 7 \\
9 \cdot 9 \pm 1 \cdot 7 \\
16 \cdot 6 \pm 4 \cdot 0 \\
46 \cdot 8^{*} \\
8 \cdot 2^{*} \\
19 \cdot 4 \pm 0\end{array}$ & $\begin{array}{c}\text { Not detected } \\
1 \cdot 1 \pm 0 \cdot 3 \\
0 \cdot 6 \pm 0.3 \\
1 \cdot 9 \pm 0 \cdot 4 \\
6 \cdot 0 \pm 2 \\
18 \cdot 8 \pm 10 \\
0.9 * \\
\text { Not detected }{ }^{(1)} \\
5 \cdot 6 \pm 2 \cdot 5 \\
11 \cdot 9 \pm 6 \cdot 7 \\
3 \cdot 1 \pm 0 \cdot 5 \\
21 \cdot 0 \pm 4 \cdot 0 \\
20 \cdot 0 \pm 4 \cdot 0 \\
\text { Not detected } \\
9 \cdot 4 \pm 3 \cdot 0\end{array}$ & $\begin{array}{c}\text { Not detected } \\
2 \cdot 1 \pm 0 \cdot 3 \\
2 \cdot 0 \pm 0 \cdot 8 \\
2 \cdot 6 \pm 0.8 \\
5 \cdot 1 \pm 0.5 \\
\text { Not detected } \\
9 \cdot 4 \pm 2 \cdot 6 \\
8 \cdot 8 \pm 1 \cdot 7 \\
10 \cdot 8 \pm 1 \cdot 6 \\
7 \cdot 7 \pm 1 \cdot 4 \\
7 \cdot 5 \pm 1 \cdot 7 \\
12 \cdot 9 \pm 2 \cdot 2 \\
13 \cdot 6 \pm 3 \cdot 3 \\
\text { Not detected } \\
\text { Not detected }\end{array}$ \\
\hline
\end{tabular}

Notes:

Standard error given with each average value of shear.

The stated shears for Hayle mud refer to measurements made under subcritical flow conditions.

$\dagger$ Value considered too low to give confidence limits.

* Phenomena detected on one occasion only.

(1) The aggregates eroded from Hayle mud were small and not easily distinguishable.

117. Considering this matter further, according to Goldstein ${ }^{18}$ the entry length $L$ is given by:

$$
L=0.693(4 m)\left(\frac{4 m U_{\mathrm{a}}}{\nu}\right)^{1 / 4}
$$

where $v$ is the kinematic viscosity, $m$ the mean hydraulic depth $w h /(w+2 h), w$ is the channel width and $h$ the depth of water. In our case $w=0.14 \mathrm{~m}$, and with $h=0.03 \mathrm{~m}$, $\nu=10^{-6}$ SI units and $U_{\mathrm{a}}=0.36 \mathrm{~ms}^{-1}$, we obtain $L=0.77 \mathrm{~m}$ which is considerably less than the distance of $3.32 \mathrm{~m}$ allowed for in our design.

118. An alternative approach is to calculate the height $\delta$ of the boundary layer at distance $y$ along the flume from the relationship: ${ }^{18}$

$$
\delta=0.37 y\left(\frac{\nu}{y U_{\mathbf{a}}}\right)^{1 / 5}
$$

With $y=3.32 \mathrm{~m}, U_{\mathrm{a}}=0.36 \mathrm{~m} / \mathrm{s}$, this gives a value of $\delta=0.075 \mathrm{~m}$ which is well in excess of the depth of water under the flow conditions needed to produce sediment erosion in the linear flume. Therefore both treatments agree in showing that the length of flume used was adequate to establish a fully developed turbulent flow, for which equation (v) is applicable when the flow is slow. This is no accident, of course, as the flume dimensions were chosen with these considerations in mind. Nevertheless, we would have preferred a somewhat longer flume for greater certainty, and to improve our fast flow experiments $(\$ 121)$ but we were limited by the size of our laboratory.

119. The possibility that secondary currents could have invalidated our derivation of fluid shear (Appendix 2) was pointed out by Professor Francis. Fortunately, in 
ancillary experiments we were able to measure the fluid shear with a drag plate as mentioned in $\S 49$, to show that secondary currents were probably not a significant disturbing factor in our linear flume experiments. The noted differences in strength between different muds generally greatly exceeded our experimental errors.

120. The need to apply a correction for unbalanced hydrodynamic forces on the drag plate was considered and calculations showed, that for the conditions under which the tests were made, the effect could be neglected. The central pivot was $1.4 \mathrm{~cm}$ wide, and the width of the drag plate was $7.5 \mathrm{~cm}$, both dimensions being measured across the channel width. Hence the pivot did not appreciably separate the fluid on either side.

121. Professor Francis and Mr Harrison rightly pointed out that the shear stress formula derived in Appendix 2 should be equally applicable to both slow and fast flow under conditions of fully developed turbulent uniform flow. The reason for not using our relationship in that case was, that under the fast flow conditions needed for erosion, uniform flow was not achieved over the limited distance downstream of the hydraulic jump $(\S 118)$. Following Boyer, ${ }^{10}$ the Manning roughness $\boldsymbol{n}=0.025$ was estimated from velocity distribution measurements made under slow flow conditions, when the flow was still uniform Under fast flow conditions, the applied fluid shear $\tau$ was equated to $\rho g R S$ where $R$ is the hydraulic radius and $S$ the slope of the energy line. According to the Manning equation:

$$
S=\frac{n^{2} U_{\mathrm{a}}^{2}}{R^{4 / 3}}
$$

where $U_{\mathrm{a}}$ is the average velocity of flow in the flume.

122. Although Mr Ackers considered our value of $n$ to be excessive, $\mathrm{Chow}^{20}$ gives similar values for soil and fine gravel, and in fact the Hayle mud was more heterogeneous than the other muds we used and contained appreciable amounts of coarse sand and fine gravel.

123. Mr Tuck pointed out that intake channels could, in principle, be designed using either laboratory tests on the mud or observations of low water channels where similar mud occurs. From our work it appears that at present laboratory tests provide the more satisfactory basis.

124. However, we feel that a study of the geometrical and flow characteristics of a number of existing intake channels, both self-scouring and silting, together with an adequate number of measurements of mud erodibility in these channels, might well lead to a relationship similar in form to that proposed by Bruun and Gerritsen ${ }^{5}$ (equation (1)) for tidal inlets. If this is so, an estimate of the stable cross-sectional area $A$ for a proposed new intake could be made from a knowledge of $Q_{\mathrm{m}}$ and the mud erodibility $\tau_{\mathrm{s}}$. The channel flow $Q_{\mathrm{m}}$ for spring tide conditions will consist of a tidal component $Q_{t}$ and a forced flow component $Q_{t}$. The latter is fixed by the power station requirements and $Q_{\mathrm{t}}$ might be determined approximately from the maximum value of $\mathrm{d}\left(A_{0} H\right) / \mathrm{d} t$ encountered during the flood tide, where $A_{0}$ is the time varying surface area of the intake basin downstream of the section of cross section $A$ under consideration and $H$ is the tide height at any instant.

125. If the stable cross section $A$ is less than the design dredged value, the channel will silt until the stable cross section is reached. It may be that little change in the dredged cross section would occur, as most of the adjustment might be produced by a reduction in $\tau_{\mathrm{s}}$ resulting from silt deposition. Conversely, if $\boldsymbol{A}$ is greater than the dredged cross section, some erosion will take place, possibly increasing $A$ slightly and $\tau_{\mathrm{s}}$ to a much greater extent, especially if $\tau_{\mathrm{a}}$ increases rapidly with depth below the bed surface as suggested by Mr Owen and discussed in $\$ 133-141$.

126. It might be thought from the above reasoning that, within wide limits, spontaneous adjustments in mud strength will compensate for any discrepancy between the dredged cross section and that required for channel stability, indicating that the channel design problem might be somewhat illusory. However, if excessive 
erosion were to precede the attainment of a stable configuration, this could lead to serious operational troubles due to the deposition of eroded silt in the cooling water circuit and condensers, particularly during periods of reduced pumping. Excessive siltation of the intake channel would merely indicate that part of the dredging costs could have been avoided.

127. Mr Tuck mentioned the possibility of foreign material being deposited at the end of the intake channel. If this caused a partial blockage, erosion would tend to scour it away. If the body resisted this, as an oil drum would for example, it might be necessary to use a crane to remove it. If a complete blockage was caused by the deposition of erodible material, wave action in an estuary might erode it somewhat, and so initiate the erosion of the channel. If however the material was too strong to be eroded by natural hydraulic forces, dredging or removal by a crane would have to be considered.

128. We are pleased that Mr Tuck considered that this Paper had contributed to an understanding of mud erosion. This advance affords a more rational basis to the design of intake channels, which have on a number of occasions been based on laboratory tests on muds. The present work confirms the utility of such tests and in this sense it is very relevant to power station intake design.

129. In the experiments with the circular flume, the underlying idea was that if muds of the same strength are subjected to similar forces, similar concentrations of particles in suspension will be produced. The similarity of particle concentrations was taken as the test criterion of similar strengths.

130. This idea was tested to some extent in a series of runs which yielded seven curves of silt concentration plotted against time for progressively increasing fluid shears applied to independent mud beds, using nominally identical Portishead mud for each run. For each curve the terminal mean silt concentration $C_{\text {T }}$ can be determined, and the initial erosion rate $E_{0}$ can then be found from the relationship:

$$
E_{0}=h\left(\frac{\mathrm{d} C}{\mathrm{~d} t}\right)_{t=0} \cdot \cdot \cdot \cdot \cdot \cdot \cdot \cdot \cdot .
$$

where $h=0.05 \mathrm{~cm}$. These results in Fig. 12 show that the terminal silt concentration is probably a measure of the (initial) erosion rate and is indeed nearly proportional to it.

131. Our outline of the likely processes in Appendix 1 was somewhat simplified, as we thought a detailed treatment would be so complex as to take us too far from our initial aim. However, Mr Owen, Mr O'Connor and Professor McDowell have raised interesting questions on the mechanics of the process which we feel deserve further consideration.

132. The eroded silt particles are carried upwards by diffusion and downwards by gravity. This would cause the particle concentration to decrease with height above the bed. This vertical variation was neglected for simplicity and an effective mean concentration was considered instead. Mr O'Connor and Professor McDowell have taken the vertical gradient into account but neglected the variation of erosion with radial distance from the central pivot and the associated radial diffusion coefficient and radial concentration gradient, and it is not clear how accurate their expression for the diffusion coefficient $\epsilon_{1}$ (equation (5)) is in this particular situation. This limits our confidence in the accuracy of their analysis somewhat, and we were surprised to see $\epsilon_{1}$ for this situation quoted to four significant figures! However, their treatment does show that the ratio of terminal silt concentrations at bed and surface levels was only 1.24 according to equation (7), so our approximation was reasonable, and our theoretical curve agrees closely with the computer solution at sampling level (Fig. 11). We never sought to imply that the concentration can change simultaneously throughout the depth as suggested in $\$ 88$, but it seems likely that the time constant for vertical mixing is much shorter than the time constant associated with the approach to a terminal silt concentration. An experiment to test this point is proposed in $\$ 142$. 


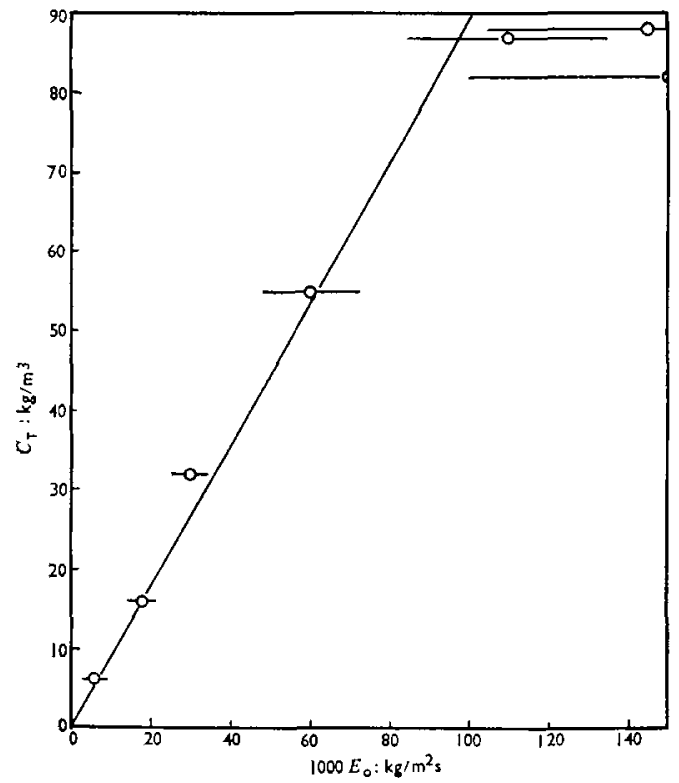

Fig. 12. Variation of silt concentration with erosion rate, lines show uncertainty of tangent slopes

133. At a more fundamental level, Mr Owen doubted our tacit assumption that erosion and deposition could occur simultaneously. On reconsideration we now recognize that sedimentation need not imply deposition, as any settling particles are likely to be immediately re-entrained from the eroding surface by fluid motions, with little chance to reform cohesive bonds with surface material. This idea gains support from the fact that a lower degree of turbulence is needed to maintain particles in suspension than to produce erosion.

134. As an alternative means of attaining the final limiting silt concentration noted experimentally, $\mathrm{Mr}$ Owen proposed in $\$ 57$ that the shear strength at a point in the silt bed increases with depth, causing the silt bed to erode down to the depth where its shear strength equals the applied fluid shear. This idea can be developed theoretically, assuming that no deposition occurs, and that the erosion rate $E$ at any instant is proportional to the difference between the applied fluid shear $r_{a}$ and the lesser shear strength of the mud $\tau_{\mathrm{s}}$.

135. Let us further assume that the dependence of mud strength on depth $y$ below the surface of the bed can be approximately represented by:

$$
\tau_{\mathrm{s}}=\tau_{0}+\beta y^{n} \quad \text {. . . . . . . . . . . . }
$$

where $\tau_{0}$ is the surface strength and $\beta$ and $n$ are positive constants depending on the nature of the sediment and its degree of compaction. Then if $E_{0}$ is the initial erosion rate when $y=0$, and $y_{0}$ is the mud depth for which $\tau_{\mathrm{s}}=\tau_{\mathrm{a}}=\tau_{0}+\beta y_{0}{ }^{n}$ :

$$
\frac{E}{E_{0}}=\frac{\tau_{\mathrm{a}}-\tau_{\mathrm{s}}}{\tau_{\mathrm{a}}-\tau_{0}}=\frac{y_{0}{ }^{n}-y^{n}}{y_{0}{ }^{n}}
$$

136. In the absence of any silt deposition, the gain in mass of suspended silt in 678 
time $t$ must equal the mass eroded, so that if $C_{z}$ be the concentration at height $z$ above the bed surface (of area $A$ ), then:

$$
A \int_{0}^{h} C_{z} \mathrm{~d} z=A \int_{0}^{t} E \mathrm{~d} t \quad . \quad . \quad . \quad . \quad . \quad .
$$

If the mean silt concentration $C$ at time $t$ is defined by:

$$
C=\frac{1}{h} \int_{0}^{h} C_{z} \mathrm{~d} z
$$

then:

$$
h C=\int_{0}^{t} E \mathrm{~d} t \text { or } \frac{\mathrm{d} C}{\mathrm{~d} t}=\frac{E}{h} \quad . \quad . \quad . \quad . \quad . \quad \text {. }
$$

137. Also the mass of silt in suspension at time $t$ must equal the mass of silt already eroded to depth $y$. If $\rho_{\mathbf{s}}$ is the density of the mud bed:

$$
\rho_{\mathrm{s}} A y=A \int_{0}^{h} C_{z} \mathrm{~d} z \text {. . . . . . . . . . }
$$

so that:

$$
y=\frac{h C}{\rho_{s}} \text { and } y_{0}=\frac{h C_{T}}{\rho_{\mathrm{s}}} \quad \text {. . . . . . . }
$$

where $C_{\mathrm{T}}$ is the terminal silt concentration, attained when $y=y_{0}$. Substituting for $y$ and $y_{0}$ in equation (17) and using equation (14):

$$
\frac{\mathrm{d} C}{\mathrm{~d} t}=\frac{E_{0}}{h}\left[1-\left(\frac{y}{y_{0}}\right)^{n}\right]=\frac{E_{0}}{h}\left[1-\left(\frac{C}{C_{\mathrm{T}}}\right)^{n}\right] \quad \text {. . . . }
$$

which becomes with the aid of the substitutions $x=C / C_{\mathrm{T}}, t_{0}=h C_{\mathrm{T}} / E_{0}$ :

$$
\int_{0}^{x} \frac{\mathrm{d} x}{1-x^{n}}=\frac{t}{t_{0}} \quad \text {. . . . . . . . . . . }
$$

138. For simple values of $n$ of practical interest, the integration of equation (21) gives:

$$
\begin{aligned}
& n=\frac{1}{2} \quad 2\left[\ln \frac{1}{1-x^{1 / 2}}-x^{1 / 2}\right]=\frac{t}{t_{0}} \\
& n=\frac{3}{4} \quad x\left[1+4 \sum_{m=1}^{\infty} \frac{x^{3 m / 4}}{3 m+4}\right]=\frac{t}{t_{0}} \\
& n=1 \quad x=1-\mathrm{e}^{-t / t_{0}} \\
& n=2 \quad x=\tanh \frac{t}{t_{0}}
\end{aligned}
$$

It is interesting to note that with this new treatment, a linear increase in mud strength with depth $(n=1)$ gives:

$$
C=C_{\mathrm{T}}\left(1-\mathrm{e}^{-E_{0} t / C} \mathrm{~T}^{h}\right)
$$

which is identical to equation (iii) of Appendix 1, except that $E$ is now replaced by $E_{0}$. In view of the good agreement between this relationship and the experimental points in Fig. 3, our limited evidence is compatible with a linear increase in strength with depth if this concept of the processes is used. However, as the solutions obtained in $\$ 106$ and 138 are formally the same, the limitations noted in $\$ 107$ still apply, and lead us to conclude that our experiments do not enable us to deduce with any accuracy how shear strength varies with depth.

139. The time variation of silt concentration is plotted in Fig. 13 for the four 


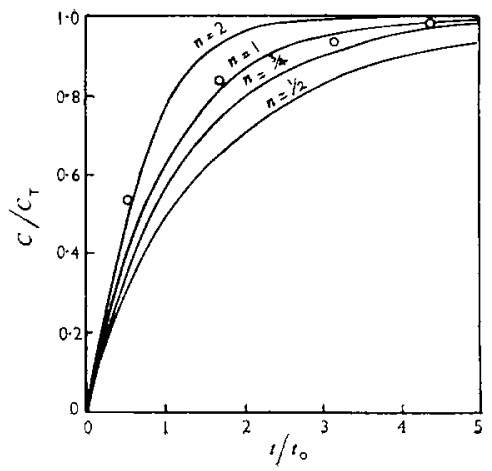

Fig. 13. Variation of silt concentration with time, points are observed values during a run at high concentration (with $C_{\mathrm{T}}=87 \mathrm{~kg} / \mathrm{cm}^{3}$ and $t_{0}=40 \mathrm{~s}$ )

values of $n$ considered above. At the suggestion of $\mathrm{Mr}$ Owen, the observed time variation of silt concentration during a test which produced a high concentration is also plotted and shows that a value of $n=1$ remains appropriate, indicating an approximately linear increase in the shear strength of mud with increasing depth. It is readily shown that this result is consistent with the fact that $C_{\mathrm{T}}$ is approximately proportional to $E_{0}$, as noted in $\$ 130$.

140. Having compared the two alternative processes by which a terminal silt concentration might be attained, it is evident that the two theoretical treatments give similar results for the experiments we performed. However, the more plausible idea is that deposition does not occur, and that the shear strength increases with depth, presumably owing to an increasing degree of compaction. This view is supported by our experiments with the linear flume, which showed that some movement of bed material occurred at relatively low shears.

141. This question could be tested by running a circular flume under steady conditions and constantly flushing out suspended silt by a continuous admission of clear saline water into the annular space. Successive samples of suspended silt extracted at constant paddle speed should show whether successive layers of mud are less easily eroded. If so, it should be possible to reach a point where almost clear water samples are obtained.

142. The time constant for vertical mixing by eddy diffusion ( $\$ 132$ ) could be determined in another experiment by adding a watertight floor to a circular flume, filling the annular space with clear water and injecting slurry at the base of the flume under steady running conditions. The time variation of concentration at a point well clear of the base could then be determined from samples of the suspension, and repeating the test for different sampling levels and speeds of rotation to gain a better understanding of the vertical diffusion process.

\section{References}

5. BruUn P. and Gerritsen F. Stability of coastal inlets, North-Holland Publishing Co., Amsterdam, 1960.

6. KRONE R. B. Flume studies of the transport of sediment in estuarial shoaling processes. University of California, Hyd. Eng. Lab. and Sanit. Eng. Res. Lab., June 1962.

7. Parthenlades E. Erosion and deposition of cohesive soils. J. Hydraul. Divn, Proc. Am. Soc. Civ. Engrs, 1965, 91 (HY1) (Jan.) 105-139. 
8. Migniot C. A study of the physical properties of various forms of very fine sediments and their behaviour under hydrodynamic action. La Houille Blanche, 1968, 23 (7) 591-620.

9. HydRAulics RESEARCH Station. River Parana: field and model investigations of a new channel connecting Buenos Aires with the delta of the River Parana. Report No. Ex 420, Feb. 1969.

10. OWEN M. W. and ODD N. V. M. A mathematical model of the effect of a tidal barrier on siltation in an estuary. Int. Conf. Utilization of Tidal Power, Halifax, Nova Scotia, Canada, May 1970.

11. Postma H. Sediment transportation and sedimentation in the estuarine environment. American Association for the advancement of Science. Publication No. 83, 1967: Estuaries.

12. Delft Hydraulics Laboratory. Report on siltation of Demarara Bar Channel and coastal erosion in British Guiana. Delft Hydraulics Laboratory, Delft, Netherlands, 1962.

13. Dobisns W. E. Effect of turbulence on sedimentation. Trans. Am. Soc. Civ. Engrs, 1943, 69 (Feb.) 235-262.

14. O'CONNOR B. A. Sediment movement in a tidal estuary. $\mathrm{PhD}$ thesis, Liverpool University, April 1969.

15. HuMBY E. J. The settling of cohesive sediments in estuaries-a literature review. Report, Dept. of Civil Engineering, University of Southampton, 1970.

16. Greated C. A. Effect of polymer additive on grid turbulence. Nature Lond., 1969, 224 (5225) 1196-1197.

17. KIrBY A. Opening address. Dredging. Institution of Civil Engineers, London, 1968, 1.

18. GoldsteIN S. Modern developments in fluid mechanics. Vol. II, Clarendon Press, Oxford, 1938, 360, 362.

19. BOYER M. C. Estimating the Manning coefficient from an average bed roughness in open channels. Trans. Am. Geophys. Un., 1954, 35 (6), 957-961.

20. Chоw V. T. Open channel hydraulics. McGraw-Hill, New York, 1959, 112. 